\title{
Enhanced Degradation of di-n-octyl phthalate (DOP) by Phenylobacterium ESF-17 isolated from waste water treatment plant
}

\author{
Wei $\mathrm{CHEN}^{1,}$, a Ke ZHANG ${ }^{1, b}$ and Jia CHEN $^{1, c}$ \\ ${ }^{1}$ College of Civil Engineering, Sichuan Agricultural University, Dujiangyan, \\ Sichuan, 611830, China \\ aEmail: chenwei@sicau.edu.cn, b Email: zhangke@sicau.edu.cn, \\ cchenjia@sicau.edu.cn
}

\begin{abstract}
Keywords: DOP, Phenylobacterium ESF-17, Biodegradation, Waste water treatment plant Abstract. In order to enhance the degradation of Di-n-octyl phthalate (DOP). One bacterial strain was isolated from activated sludge of waste water treatment plant(WWTP) using Di-n-octyl phthalate (DOP) as the sole source of carbon and energy. According to the phylogeny of 16S rDNA sequence, the bacterial strain ESF-17 was identified as Phenylobacterium sp. Biodegradation of DOP by Phenylobacterium ESF-17 was investigated. Results showed that the optimum $\mathrm{pH}$ and temperature for DOP degradation by Phenylobacterium ESF-17 were 8.0 and $25^{\circ} \mathrm{C}$. The strain exhibited higher degradation efficiencies and growth rates in alkalinity than in acidity. The strain could degrade approximately $93 \%$ of $400 \mathrm{mg} / \mathrm{L}$ DOP shorter alkyl chain PAEs, whereas the degradation efficiency of longer alkyl chain PAEs were relatively poor. The results suggest that Phenylobacterium ESF-17 may represent a promising application for DOP bioremediation.
\end{abstract}

\section{Introduction}

Di-n-octyl phthalate (DOP), as a prior pollutant for control, has been widely detected in environment. DOP is the member of phthalic acid esters (PAEs), which are widely used as plasticizers, building materials, additives in plastics and cosmetics production. [1] DOP is one of most common used PAEs. Three of the phthalic acid esters, namly, di-methyl phthalate (DMP), di- $n$-butyl phthalate (DBP) and di-n-octyl phthalate (DOP) have been listed as priority pollutants by China National Environmental Monitoring Center and the US Environmental Protection Agency [2] PAEs have received increasing attention in recent years due to their widespread produce, use and disposal, as a result they are also ubiquitous in environments. Moreover, These compounds are concerning because they have been shown to interfere with the reproductive system of human and animal. Phthalate esters (PAEs) are a prominent group of environmental pollutants and endocrine-disrupting compounds in many environmental. In addition, DOP can be taken up by crops and thus enter the food supply chain system, which may harm aquatic organisms and human health[3,4,5].DOP in one member of PAEs.

In recent years, many researches have been conducted to look for better way to degrade DOP including physical and chemical methods. Previous studies have revealed that DOP and DBP can be removed by natural processes in natural environments, such as hydrolysis, photo degradation and biodegradation $[6,7,8]$. Due to the low rate of chemical hydrolysis and photolysis of DOP, metabolic breakdown of this widespread pollutant by microorganisms is considered to be the major route. Several PAEs-degrading bacterial strains belonging to the genera Sphingomonas, Pseudomonas, Rhodococcus, Microbacterium and Gordonia have been isolated from different environments, such as active sludge. $[7,8]$

In the present paper, a DOP-degrading bacterium was isolated from active sludge and identified by $16 \mathrm{~S}$ rDNA sequence. The biodegradation kinetics and different environmental factors affecting this process were investigated. The result from this study is expected to improve current understanding of the bioremediation of DOP and find more high effective DOP-dergading strains. 


\section{Materials and methods}

\section{Reagents and chemicals}

DOP (99.5\% purity) for the experiment was purchased from Chengdu Kelong Chemical Reagent Co., Ltd., All the chemical reagents were of analytical grade and all solvents(Ethyl acetate and methanol) were of HPLC grade purchased from Tianjing kemiou Reagent Co., Ltd.

The MM contained (1L): $\mathrm{MgSO}_{4} 7 \mathrm{H} 2 \mathrm{O} 0.5 \mathrm{~g}, \mathrm{~K}_{2} \mathrm{HPO}_{4} 1.70 \mathrm{~g}, \mathrm{FeSO}_{4} \cdot 7 \mathrm{H}_{2} \mathrm{O} 0.05 \mathrm{~g}$, and $\mathrm{NaNO}_{3} 0.5$ $\mathrm{g},\left(\mathrm{NH}_{4}\right)_{2} \mathrm{SO}_{4} 1.0 \mathrm{~g}, \mathrm{Na}_{2} \mathrm{MoO}_{4} 0.0024 \mathrm{~g}, \mathrm{CaCl}_{2} \cdot 2 \mathrm{H}_{2} \mathrm{O} 0.04 \mathrm{~g}, \mathrm{FeCl}_{3} 0.0018 \mathrm{~g}$.

The nutrient broth (NB) for bacteria enrichment consisted of beef extract $3 \mathrm{~g}$, peptone $5 \mathrm{~g}, \mathrm{NaCl} 5 \mathrm{~g}$, $\mathrm{pH}$ 7.2.Nutrient agar plates were made using NB supplemented with $2 \%$ agar.

\section{Enrichment and isolation of DOP Strains}

The enrichment procedure was accroding to $\mathrm{Wu}$ [9] with some modifications. Initially, $5.0 \mathrm{~g}$ of sludge was added to a 500-ml Erlenmeyer flask containing $200 \mathrm{ml}$ of MM solution amended with concentration of $100 \mathrm{mg} / \mathrm{l}$ DOP. The suspension was incubated for 6 days in the dark at $25^{\circ}$ Caccording to pre-experiment on a rotary shaker operated at $140 \mathrm{rpm}$. Subsequently, $2 \mathrm{ml}$ of the enrichment culture was serially transferred five times to fresh medium incubated under the same conditions. At the same time, in the process of transfer, containing a higher concentration of DOP200-500 mg/l each time. Then the final enrichment was streaked onto MM agar plates supplemented with a mixture of DOP $(500 \mathrm{mg} / \mathrm{l})$ and incubated 1 week at $25^{\circ} \mathrm{C}$. Presumptive colonies were picked on the basis of differences in colony morphology and coloration and re-streaked onto MM agar plates amended with DOP. The bacterial isolates were further purified by streaking on LB Nutrient Agar plates and then re-streaked onto MM agar plates with and without DOP to confirm their degradation abilities. Isolates can grow in the presence of DOP but not in their absence were selected for further study.

\section{Amplification of 16S rDNA}

Extraction kit (Sangon Corporation, Shanghai, China)was used for the extraction of bacterial genomic DNA according to the manufacturer's instructions. Further identification was performed by $16 \mathrm{~S}$ rDNA gene sequencing. and then about 1500 bp length of 16S rRNA was amplified through PCR by using the bacterial universal primer 27F (50-AGAGTTTGATCCTGGCTCAG-30) and 1492R (50-GGCTACCTTGTTACGACTT-30). PCR was performed ( Bio-Rad USA) under the following conditions: preheated at $95{ }^{\circ} \mathrm{C}$ for $2 \mathrm{~min}$; then denatured at $94{ }^{\circ} \mathrm{C}$ for $1 \mathrm{~min}$, annealing at $56{ }^{\circ} \mathrm{C}$ for 1 min, extended at $72{ }^{\circ} \mathrm{C}$ for $3 \mathrm{~min}$ for 30 cycles, last extended at $72^{\circ} \mathrm{C}$ for $8 \mathrm{~min}$.

\section{Sequence analysis of strain}

Purified PCR product was directly sequenced. The sequence data of the closest relatives were retrieved from NCBI database and aligned with CLUSTALW with all parameters set at their default values. A phylogenetic tree was then constructed using the neighbor-joining method with MEGA 6.0 software. The trees were validated using bootstrap analysis performed with 1000 replicates.

\section{Degradation experiments of Phenylobacterium ESF-17}

The following environmental factors were assayed to investigate their effects on DOP degradation within $60 \mathrm{~h}$ of cultivation at a $140 \mathrm{rpm}$ shaking rate. Temperature $\left(10,15,20,25\right.$ and $\left.30^{\circ} \mathrm{C}\right)$; Initial $\mathrm{pH}$ value $(4.0,5.0,6.0,7.0,8.0,9.0)$; Initial DOP concentration $(100 \mathrm{mg} / \mathrm{l}, 200 \mathrm{mg} / 1,300 \mathrm{mg} / \mathrm{l}, 400$ $\mathrm{mg} / 1,500 \mathrm{mg} / \mathrm{l})$. PAEs(DBP, DOP, DEP, DMP, DEHP and DPP)

\section{Analysis method}

Concentration of DOP in the supernatant solution was performed using high performance liquid chromatography (HPLC) (Aglient 1200 series). The column temperature was $40^{\circ} \mathrm{C}$. The volume of the injected samples was 40 $\mu$; Chromatography column was Inertsil ODS-2151-K. 6× $150 \mathrm{~mm}$. 


\section{Results and discussion}

\section{Isolation and identification of the DOP-degrading bacterium}

Following 35 days enrichment, several DOP-degrading strains were isolated from the activated sludge. One strain shown high biomass and high degradation efficiency was selected for furtherinvestigation. Phylogenetic of the 16Sr RNA gene (Fig.1) revealed strain Phenylobacterium ESF-17 clustered with members of the genus Pseudomonas, and had a 100\% sequence similarity with Pseudomonas amygdale.

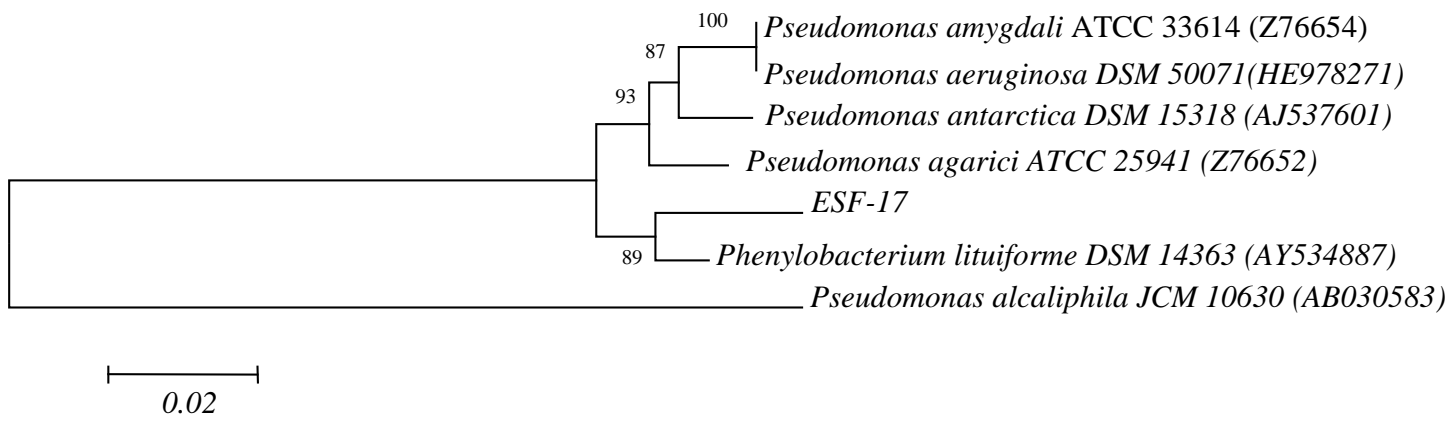

Fig. 1. Phylogenetic tree derived from 16S rRNA gene sequence of Phenylobacterium ESF-17 and sequences of related species. Distances were calculated using neighbor-joining method. Numbers at branch nodes are bootstrap values based on 1000 re-samplings. Scale bars represent 0.002 substitutions per site.

\section{Effects of temperature on DOP biodegradation}

The strain was cultivated at condition of $25^{\circ} \mathrm{C}, 500 \mathrm{mg} / \mathrm{L}$ and $\mathrm{pH} 8$, at a $140 \mathrm{rpm}$ shaking rate based on pre-experiment. The effects of temperature on the degradation of DOP in the culture medium were tested after incubation $60 \mathrm{~h}$. The results showed that the optimal temperature for degradation was $25^{\circ} \mathrm{C}$. The temperature are not consistent with previous reports [12][13]. There is no significant difference between $20^{\circ} \mathrm{C}$ and $25^{\circ} \mathrm{C}(P<0.05)$.

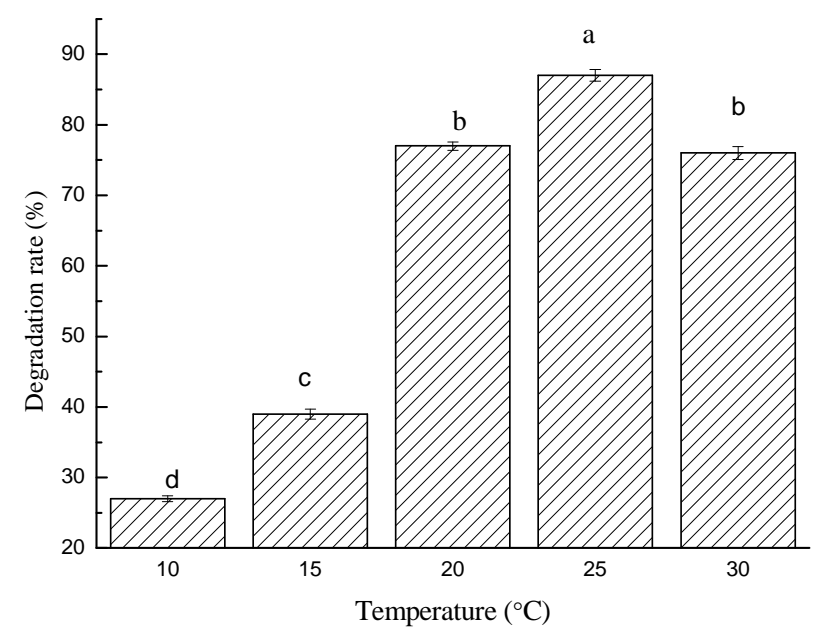

Fig. 2. Effect of temperature on degradation of DOP

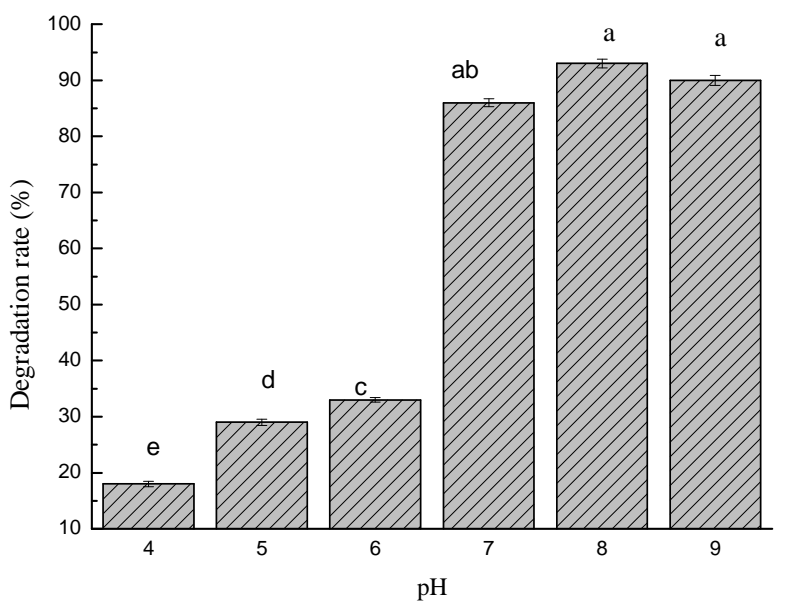

Fig. 3. Effect of $\mathrm{pH}$ and temperature on degradation of DOP

\section{Effects of initial pH on DOP biodegradation}

In order to investigate the effect of $\mathrm{pH}$ on strain degradation, different $\mathrm{pH}$ value was setted.Fig.3.showed the Effects of $\mathrm{pH}$ (4.0-9.0) on DOP biodegradation at an initial concentration of $400 \mathrm{mg} / \mathrm{L}$. We observed that the consortium exhibited higher degradation efficiencies and growth rates in alkalinity than in acidity. The highest DOP degradation rate was achieved at $\mathrm{pH} 8.0(87.4 \%)$. The reported optimal $\mathrm{pH}$ values in degrading of various pollutants by other genus are ranging from 7.0 
to 8.0[10] [11].The degradation rate of DOP decreased rapidly when $\mathrm{pH}$ decreased from 8.0 to 4.0. The results indicate that $\mathrm{pH}$ of 8.0 and 9.0 are optimal for DOP degradation and growth.

\section{Effects of initial concentration on DOP biodegradation}

In order to exame the effect of initial DOP concentrations on degrading efficiency by Phenylobacterium ESF-17. Experiment was conducted under DOP concentrations ranging 100, 200, 300,500 and $600 \mathrm{mg} / \mathrm{L}$. Bacterial growth is concentration sensitive. As shown in Fig. 4 the DOP degradation rate decreased rapidly as concentration increased from 500 to $600 \mathrm{mg} / \mathrm{l}$. In general, the strain had a high degradation rate at the different concentration under $400 \mathrm{mg} / \mathrm{L}$.

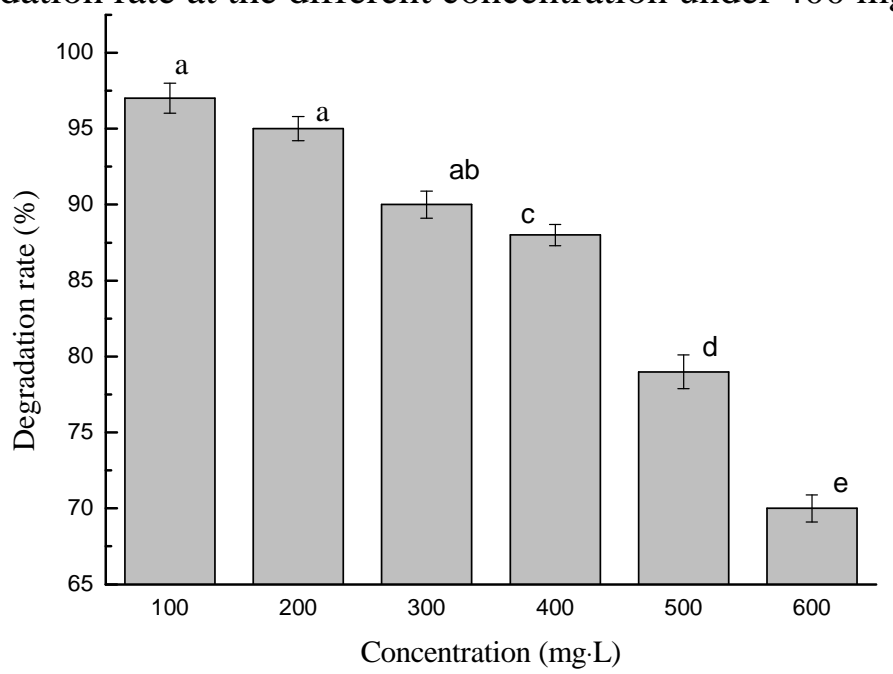

Fig. 4. Effect of initial concentration on degradation of DOP

\section{Degradation of PAEs by bacteria}

In order to investigate the degradation ability of the consortium to other commonly used PAEs in environment, the consortium was cultured in MSM supplemented with DBP, DOP, DEP, DMP, DEHP and DPP at $30{ }^{\circ} \mathrm{C}$. Fig. 5 presents the degradation rates for six PAEs and the biomass values of the consortium. The lowest biomass along with the lowest degradation rate was observed in DIOP. The consortium could utilize DBP, DOP, DEP, DMP, DEHP and DPP as the sole source of carbon and energy for growth. The degradation rates of DMP, DEP, DBP were higher than that of DOP, DEHP and DPP. The result indicated that shorter alkyl chain PAEs were degraded rapidly by consortium, while PAEs with longer alkyl chains were more difficult to be degraded.

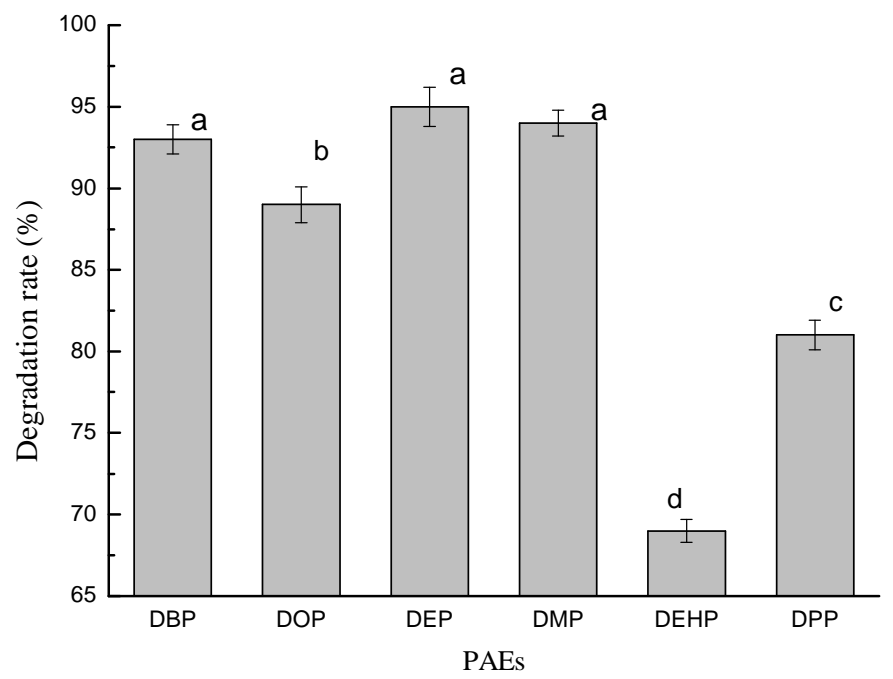

Fig.5. Degradation of other PAEs by isolate 


\section{Conclusions}

A strain Phenylobacterium ESF-17 that can degrade DOP was isolated from activated sludge. Based on 16S rRNA sequence analysis, the strain was identified as Pseudomonas amygdali. This study investigated the optimal $\mathrm{pH}$, initial concentration and temperature for DOP degradation in MM. The optimum biodegradation $\mathrm{pH}$ and temperature was 8.0 and $15^{\circ} \mathrm{C}$, respectively. The optimal concentration was no more than $400 \mathrm{mg} / \mathrm{l}$.The study also showed under optimal $\mathrm{pH}$ and temperature condition, strain Phenylobacterium ESF-17 was capable of degrading DOP up to 94\% in 6d incubation, which suggest that Pseudomonas amygdali. Phenylobacterium ESF-17 is a potential candidate for DOP degradation.

\section{Acknowledgement}

This work was financially supported by Science and Technology Support Project of Sichuan education bureau (No. 2014NZ0044) and Science and Technology Project of Sichuan Environment protection Bureau (No. 2011HB001).

\section{References}

[1] A.C. Staple, D.R. Peterson, T.H. Parkerton, W.J. Adams, The environmental fate of phthalic esters: a literature review, Chemosphere 35 (1997) 667-749.

[2] P. Wang, S. Wang, C.Q. Fan, Atmospheric distribution of particulate- and gas-phase phthalic esters (PAEs) in a metropolitan city, Nanjing, East China, Chemosphere 72 (2008) 1567-1572.

[3] F. Wang, X.H. Xia, Y.J. Sha, Distribution of phthalic acid esters in Wuhan section of the Yangtze River, China, J. Hazard. Mater. 154 (2008) 317-324.

[4] Lu Y, Tang F, Wang Y, Zhao J, Zeng X, Luo Q, et al. Biodegradation of dimethyl phthalate, diethyl phthalate and di-n-butyl phthalate by Rhodococcus sp. L4 isolated from activated sludge. J Hazard Mater, 2009;168:938-43.

[5] Wu X, Wang $\mathrm{Y}$, Liang $\mathrm{R}$, Dai Q, Jin $\mathrm{D}$, Chao $\mathrm{W}$. Biodegradation of an endocrinedisruptingchemical di-n-butyl phthalate by newly isolated Agrobacterium sp.and the biochemical pathway. Process Biochem, 2011;46:1090-4.

[6] Zhixing $\mathrm{H}$, Hailong $\mathrm{X}$, Biodegradation of di-n-butyl phthalate by a stable bacterial consortium, HD-1,enriched from activated sludge. Bioresource Technology, 2013;128:526-532.

[7] Qiaofeng W,JiabaoY.Degradation kinetics and metabolic pathway of a strain for di-n-butyl phthalate degrading. Fuel Chem Processes, 2013;44: 41-44.

[8] Qiong W, Hui L, Li-Sheng Ye, Biodegradation of Di-n-butyl phthalate esters by Bacillus sp. SASHJ under simulated shallow aquifer condition.International Biodeterioration \& Biodegradation, 2013;76 : 102-107.

[9] Xueling W, Renxing L, Qinyun D, Complete degradation of di-n-octyl phthalate by biochemical cooperation between Gordonia sp. strain JDC-2 and Arthrobacter sp. strain JDC-32 isolated from activated sludge.Journal of Hazardous Materials ,2010;176: 262-268.

[10]Lu Y, Tang F, Wang Y, Zhao J, Zeng X, Luo Q, et al. Biodegradation of dimethyl phthalate, diethyl phthalate and di-n-butyl phthalate by Rhodococcus sp. L4 isolated from activated sludge. J Hazard Mater, 2009;168:938-43.

[11] Khleifat K. Biodegradation of phenol by Ewingella americana: effect of carbon starvation and some growth conditions. Process Biochem, 2006;41:2010-6.

[12] Wu, X.L., Wang, Y.Y,Degradation of di-nbutyl phthalate by newly isolated Ochrobactrum sp. Bulletin of Environmental Contamination and Toxicology,2010; 85:235-237.

[13] S. Chatterjee, T.K. Dutta, Metabolism of butyl benzyl phthalate by Gordonia sp. strain MTCC 4818, Biochem. Biophys. Res. Commun. 309 (2003) 36-43. 